PSICOLOGIA, SAÚDE \& DOENÇAS, 2018, 19(3), 789-804

ISSN - 2182-8407

Sociedade Portuguesa de Psicologia da Saúde - SPPS - www.sp-ps.pt

DOI: http://dx.doi.org/10.15309/18psd190325

\title{
WEB-BASED COMPUTER-DELIVERED INTERVENTIONS FOR ILLICIT DRUG USERS: A REVIEW
}

\author{
Mariana Cançado ${ }^{1}$, Andressa Gumier ${ }^{1}$, Nathálya Ribeiro ${ }^{1}$, Ana Paula Fernandes ${ }^{1}$, \& Laisa Sartes ${ }^{1 \square}$ \\ ${ }^{1}$ Psychology Department, Universidade Federal de Juiz de Fora, Juiz de Fora, Brasil, \\ marianaflcancado@gmail.com, andressabgumier@gmail.com, nsribeiroufjf@gmail.com, \\ anapaulatorres.ufjf@hotmail.com, laisa.sartes@ufjf.edu.br
}

\begin{abstract}
Drug use-related disorders indicate a public health problem in many countries. Despite the high number of users in Brazil, there are gaps in the offering of specialized treatment for drug users. Web-based or computer-assisted interventions can facilitate access to interventions, but no research about this resource and its use with this specific population could be found in Brazil. To analyze, through an exploratory study, five randomized controlled clinical trials and two pilot trials for computer-delivered therapeutic interventions for illicit substance users. We included papers published between January 2014 and October2014 and were available on the PubMed, PsychInfo, Scielo and Lilacs databases. The computer-delivered interventions were directed towards adult cannabis, cocaine, opioids and benzodiazepine users that were undergoing treatment in a clinic or through the internet. Some interventions had a mediator or were self-guided, and most were brief interventions, based on cognitive behavioral therapy. The results indicate that this method of treatment is a promising alternative or complement to existing interventions for illicit drug users. Some of the observed indicators were a reduction of drug consumption compared to the control group, positive ratings of the computer-delivered sessions and positive therapeutic alliance scores.
\end{abstract}

Keywords: substance-related disorders, telemedicine, cognitive therapy, therapy, computer-assisted, street drugs

\section{INTERVENÇÕES COMPUTADORIZADAS PARA USUÁRIOS DE DROGAS ILÍCITAS: UMA REVISÃO}

RESUMO: Os transtornos relacionados ao consumo de drogas evidenciam um problema de saúde pública em muitos países. Porém, mesmo com o consumo existente no Brasil, há lacunas na oferta de tratamento especializado para os usuários de drogas. Perante esta lacuna, os tratamentos por internet ou computadorizados podem facilitar o acesso às intervenções. Porém, não foram encontradas investigações no país sobre este recurso para esta população específica. Analisar de forma exploratória cinco ensaios clínicos randomizados e dois estudos piloto sobre intervenções terapêuticas por computador para usuários de substâncias psicoativas ilícitas. Foram incluídos estudos empíricos encontrados nas bases de dados PubMed, PsychInfo, Scielo e Lilacs, publicados entre janeiro de 2004 e outubro de 2014. As intervenções computadorizadas

\footnotetext{
St José Lourenço Kelmer-Psychology Department-Human Sciences Institute- Universidade Federal de Juiz de Fora -Juiz de Fora-MG - Brasil ZIP code: 36036-900. e-mail: laisa.sartes@ ufjf.edu.br
} 


\section{WEB-BASED INTERVENTIONS FOR ILLICIT DRUG USERS}

eram direciondas para adultos, usuários de maconha, cocaína, opióides e benzodiazepínicos, que estavam em tratamento em clínica ou por internet. Algumas intervenções tinham participação de um mediador ou eram auto aplicadas e a maioria era breve, baseada na terapia cognitivo-comportamental. Os resultados encontrados indicam que esta modalidade de tratamento pode ser promissora como uma alternativa de tratamento ou complemento as intervenções existentes para usuários de drogas ilícitas. Alguns indicadores observados são a diminuição do consumo da droga quando comparado ao grupo controle, avaliação positiva da intervenção e medidas de relação terapêutica positivas.

Palavras-chave: transtornos relacionados ao uso de substâncias, telemedicina, terapia cognitiva, drogas ilícitas

Recebido em 14 de Março de 2017/ Aceite em 06 de Novembro de 2018

Drug use-related disorders are a public health problem in various countries, including Brazil. A Brazilian drug report (Duarte, Stempliuk, \& Barroso, 2009)cites that drug use is related to HIV and hepatitis contaminations on injected drug users, hospitalizations as result of drug use on the public health system, mortality, retirement and pensions associated to drug use and drug trafficking and possession. Such factors illustrate the effects and social costs of substance abuse. Two nationwide surveys show that there was an increase in both licit and illicit substance use between 2001 and 2005. Despite this increase insubstance consumption, fewer users have looked for treatment: from $4.0 \%$ in 2001 to $2.9 \%$ in 2005 (Carlini, et al., 2005).

Even though it's an important public health problem in Brazil, only 57\% of the population was covered by psychosocial attention centers (Centros de AtençãoPsicossocial - CAPS) in 2009 (Duarte, Stempliuk, \& Barroso, 2009). The situation is worse when it comes to treatment for alcohol and other drug dependents, since only part of the services is destined to that population, and it isn't enough to cover the entire nation's territory, which limits their access to specialized treatment.

Some other factors that can hinder the users' access to other forms of treatment, according to Corrigan (2004), the stigma associated to drug users, especially illicit drugs, and individuals with mental disorders negatively impacts treatment-seeking because those individuals are labeled negatively. Another factor is the high cost of treatments, which make them available to only a small part of the population (Brown, et al., 2009). Schaub et al. (2013) also noted the difficulties of getting to treatment centers and their operating hours, because users whose work hours coincide with a treatment center's may not be able to get treatment.

Thus, web-based or computer-based treatments can help reach people who don't want to risk being stigmatized and can also be a cost-effective treatment option (Olmstead, Ostrow, \& Carroll, 2010; Schaub, et al., 2013). Aside from those factors, it's expected that the higher flexibility of online interventions in regard to time of application will help reach a higher number of people and offer treatment to those that are not close to specialized treatment centers (Tait et al., 2012).

According to Gregório (2012), there is a demand for research on alcohol and drug treatments and the use of new technologies for capacitation of health care professionals. Some reviews have been trying to evaluate the effects of computer-based interventions for alcohol and tobacco disorders (Balhara \& Verma, 2014; Dedert, et al., 2014), but illicit drug interventions haven't received the same amount of attention (Copeland \& Martin, 2004; Tait et al., 2014). 
The aim of this systematic review was to analyze literature on computer-based therapeutic interventions for illicit drug users published between 2004 and 2014. There was a focus on the identification of the main bibliometric indicators andin making an exploratory analysis of the contents of the studies.

\section{METHOD}

We chose four databases were chosen for this review: Pubmed, Psycinfo, Lilacs and Scielo. The thesaurus of each database was used to select the descriptors. For the Pubmed search MeSH (Medical Subject Headings) was used, the Thesaurus of Psychological Index Terms was used on Psycinfo, and for Lilacs and ScieloDeCS (DescritoresemCiências da Saúde), which is based on $\mathrm{MeSH}$, was used.

The terms used for the search are shown in Table 1. The descriptors referring to each field relevant for the search (computer-assisted intervention, drug use and therapeuticalapproach) were manually combined with the Boolean operator "AND" so that the search was restricted to abstracts that contained both terms.

Table 1.

Descriptors used for search articles in the databases

\begin{tabular}{|c|c|c|c|}
\hline \multicolumn{4}{|c|}{ Descriptors Used } \\
\hline $\begin{array}{l}\text { Therapeutic } \\
\text { approach }\end{array}$ & Intervention & Drugs & Database \\
\hline $\begin{array}{l}\text { Cognitive } \\
\text { therapy }\end{array}$ & $\begin{array}{l}\text { Remote consultation; telemedicine; } \\
\text { therapy, computer assisted }\end{array}$ & $\begin{array}{l}\text { Substance related disorders, street } \\
\text { drugs, cocaine-related disorders, } \\
\text { amphetamine-related disorders, } \\
\text { inhalant abuse, marijuana abuse, } \\
\text { opioid-related disorders, morphine } \\
\text { dependence, crack cocaine, heroin } \\
\text { dependence }\end{array}$ & Pubmed \\
\hline $\begin{array}{l}\text { Cognitive } \\
\text { Therapy; } \\
\text { Cognitive } \\
\text { Behavior } \\
\text { Therapy }\end{array}$ & $\begin{array}{l}\text { Computer assisted therapy; } \\
\text { computer mediated communication; } \\
\text { online therapy; Telemedicine }\end{array}$ & $\begin{array}{l}\text { Drug usage; drug abuse; drug } \\
\text { dependency; addiction; polydrug } \\
\text { abuse; drug addiction; inhalant } \\
\text { abuse; marijuana usage; opiates; } \\
\text { heroin addiction }\end{array}$ & Psycinfo \\
\hline $\begin{array}{l}\text { Cognitive } \\
\text { Therapy }\end{array}$ & $\begin{array}{l}\text { Therapy, computer assisted; } \\
\text { telemedicine; remote consultation }\end{array}$ & $\begin{array}{l}\text { Substance-related disorders; street } \\
\text { drugs; cocaine-related disorders; } \\
\text { amphetamine-related disorders; } \\
\text { inhalant abuse; marijuana abuse; } \\
\text { opioid-related disorders; heroin } \\
\text { dependence }\end{array}$ & $\begin{array}{l}\text { Lilacs and } \\
\text { Scielo }\end{array}$ \\
\hline
\end{tabular}

Papers we included in the review were empirical studies of computer-assisted or computer-based interventions for illicit substance users published between January 2004 and October 2014. Reviews, books and book chapters, dissertations, study protocols and theses were excluded. Phonedelivered interventions were also excluded. From the search with the previously mentioned descriptors, articles were only found on the Pubmed and Psycinfo databases. Those articles were 


\section{WEB-BASED INTERVENTIONS FOR ILLICIT DRUG USERS}

exported to the free software My Endnote Web, available at the website https://www.myendnoteweb.com.

The search on the databases resulted in 248 articles, 71 of them from the Pubmed database and 177 from the Psycinfo database. Duplicate articles within each database were identified and removed, resulting in 42 articles from PubMed and 103 from Psycinfo, for a total of 145 articles. After duplicate articles between both databases were removed, 133 articles remained. The titles and abstracts of these articles were read, and 123 articles were then excluded for not fitting fulfilling the inclusion criteria or fulfilling the exclusion criteria. Seventy of these articles were excluded because their interventions were directed towards other populations or disorders, 16 were excluded because their interventions were aimed at licit drugs (alcohol and tobacco), 25 were excluded for being reviews, dissertations, study protocols or theses and 12 articles were excluded because the interventions were directed towards alcohol/tobacco and other drug users.

The article selection process can be seen on Figure 1. Ten articles were analyzed, but in the process it became clear that 3 more articles did not fulfill the inclusion criteria.Two of those articles did not fit the inclusion criteria due to being study protocols and one because it was an intervention aimed towards drugs and alcohol users. These studies were not previously removed because it wasn't clear from the titles and abstracts if they were in the inclusion or exclusion categories. 
Data bases: PubMed,

PsycINFO, Lilacs and Scielo
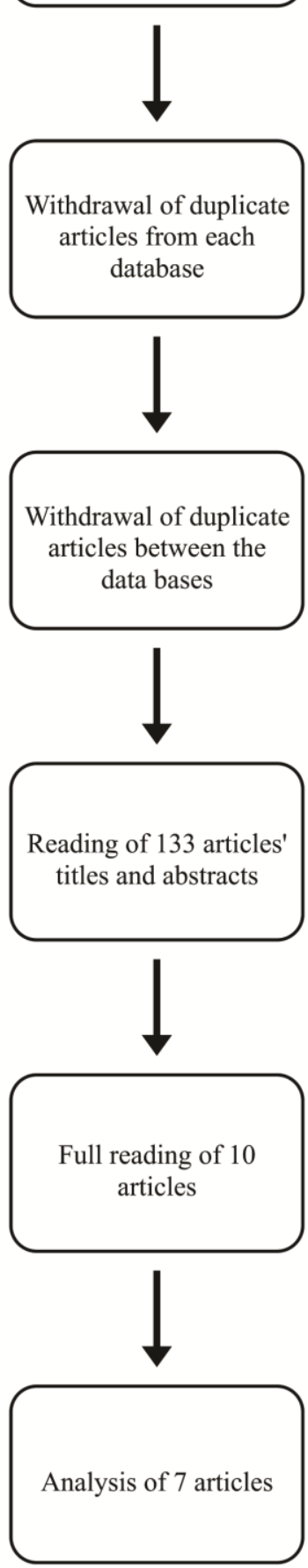

Total of 248 articles

71 at PubMed

177 at PsycINFO

Total of 145 articles

42 at PubMed

103 at PsycINFO

Removal of 12 articles

Withdrawal of 123 articles due to the inclusion criteria

Withdrawal of 3 articles due to the inclusion criteria

Figure. 1

Methodology used for selecting articles 


\section{WEB-BASED INTERVENTIONS FOR ILLICIT DRUG USERS}

Seven articles were included for this review and will be analyzed further. The reading and analysis of each article was done by peers. For each article, the following bibliometric indicators were described: authors, language, year and country of publishing and journal where it was published.

The choosing of the type of document to be studied was made beforehand, according to the previously mentioned criteria. After a first reading a few indicators were chosen, and then the material was more thoroughly explored. The codification was made in an exploratory manner followed by categorization. The following categories were observed: the theoretical approach that served as a foundation for the practical intervention, the type of drug, research design, the length of the intervention and the means through which it was applied, the target population, whether were any follow-up assessments and results found. Besides those categories, the methodology of each study was analyzed to question the results found by them.

\section{RESULTS AND DISCUSSION}

\section{Bibliometric indicators}

All seven analyzed articles were published in English, one of them published in the United Kingdom, three in the United States, one in the Netherlands and two in Canada. The articles were published in different journals. Two articles were published in the Journal of Medical Internet Research, and the others were published in Drug and Alcohol Dependence, Journal of Dual Diagnosis, Experimental and Clinical Psychopharmacology, The American Journal of Psychiatry and Drug and Alcohol Review.

Within the period chosen for the article search, from January 2004 to October 2014, no articles published before 2008 were found. In 2008 only one article was published, and none published in 2009 and 2010 were found. Two articles were published in 2011, followed by two in 2012. In 2013 only one article was found, and in 2014, until October, one article was found.

The frequency of articles in this area fluctuates through the years, and there aren't many published articles. The articles published in this area of research are recent, suggesting that this is still an emerging area of research.

Content analysis

An overview of each paper's objectives and results can be found on Table 2. After reading and analyzing the articles, the previously mentioned categories were defined. Those categories and the results found in the analyzed papers are discussed belo 
Table 2.

Aims and results of the seven studies included in the content analysis

\begin{tabular}{|c|c|c|c|c|}
\hline Year & Author & Title & Objectives & Results \\
\hline 2008 & $\begin{array}{l}\text { Bickel et } \\
\text { al. }\end{array}$ & $\begin{array}{l}\text { Computerized behavior } \\
\text { therapy for opioid- } \\
\text { dependent outpatients: A } \\
\text { randomized controlled trial }\end{array}$ & $\begin{array}{l}\text { To evaluate the efficacy of an interactive } \\
\text { computer-based behavioral therapy } \\
\text { intervention. Compare a therapist- } \\
\text { delivered community reinforcement } \\
\text { approach treatment with computer-assisted } \\
\text { CRA treatment and with standard } \\
\text { treatment. }\end{array}$ & $\begin{array}{l}\text { The computer-assisted and therapist-delivered CRA treatment } \\
\text { groups produced significantly greater weeks of continuous } \\
\text { abstinence relative to the standard treatment group. The } \\
\text { therapist and computer-assisted groups also showed more } \\
\text { negative (no positive result for drugs) urinalysis results. ASI } \\
\text { (Addiction Severity Index) results were reduced in all groups. } \\
\text { Patient-therapist contact time was significantly reduced in the } \\
\text { computer-assisted group. Therapeutical alliance scores were } \\
\text { high in all groups. }\end{array}$ \\
\hline
\end{tabular}

2011 Budney An initial trial of a

et al. computerized behavioral intervention for cannabis use disorder

2011 Parr et Acceptability of cognitiveal.

To describe the design and development of Urine sample results were similar for both groups. Time spent a computer-assisted version of MET/CBT/CM, and compare results of its group. There was no significant difference between groups in initial testing to those of traditional therapist-delivered treatment. regards to the percentage of participants that reached at least 4,6 or 8 weeks of abstinence

To assess the outcomes of an uncontrolled behaviour therapy via the case series of an Internet-based cognitive internet for cessation of benzodiazepine use

behavior therapy for benzodiazepine cessation.
The newsletters were rated easy to read and as having useful information. $91 \%$ of participants accessed the newsletters at least once. The average number of accesses was $7,3 \pm 8,34$ times. The 3-month assessment revealed a significant change in benzodiazepine use and in the dependence and self-efficacy scores. At 6 months, the 3 month reductions were retained. 
WEB-BASED INTERVENTIONS FOR ILLICIT DRUG USERS

\begin{tabular}{|c|c|c|c|c|}
\hline 2012 & $\begin{array}{l}\text { Acosta } \\
\text { et al. }\end{array}$ & $\begin{array}{l}\text { A web-based behavior } \\
\text { therapy program influences } \\
\text { the association between } \\
\text { cognitive functioning and } \\
\text { retention and abstinence in } \\
\text { clients receiving methadone } \\
\text { maintenance treatment }\end{array}$ & $\begin{array}{l}\text { To characterize multiple dimensions of } \\
\text { cognitive functioning in methadone } \\
\text { maintenance clients enrolled in a study to } \\
\text { evaluate a web-based intervention; } \\
\text { Examine the impact of baseline cognitive } \\
\text { functioning on retention and treatment } \\
\text { outcome in the intervention study; and } \\
\text { determine whether cognitive functioning } \\
\text { had a differential impact on these } \\
\text { outcomes across treatment conditions }\end{array}$ & $\begin{array}{l}\text { Lower cognitive scores predicted less abstinence weeks for } \\
\text { the regular treatment group, but not for those in the computer } \\
\text { intervention group. Lower scores of cognitive functioning in } \\
\text { patients that only received the usual treatment predicted worse } \\
\text { treatment outcomes than those who received the usual } \\
\text { treatment and the computer-assisted intervention. }\end{array}$ \\
\hline 2012 & $\begin{array}{l}\text { Schaub } \\
\text { et al. }\end{array}$ & $\begin{array}{l}\text { Web-based cognitive } \\
\text { behavioral self-help } \\
\text { intervention to reduce } \\
\text { cocaine consumption in } \\
\text { problematic cocaine users: } \\
\text { Randomized controlled } \\
\text { trial. }\end{array}$ & $\begin{array}{l}\text { To test the feasibility and effectiveness of } \\
\text { a fully automated, web-based self-help } \\
\text { intervention as an alternative to outpatient } \\
\text { treatment services for cocaine users. }\end{array}$ & $\begin{array}{l}\text { The experimental group completed more modules than the } \\
\text { control group. Retention in the experimental group was } \\
\text { significantly higher than in the control group. Weekly quantity } \\
\text { of cocaine used decreased equally in both groups. }\end{array}$ \\
\hline 2013 & $\begin{array}{l}\text { Rooke et } \\
\text { al. }\end{array}$ & $\begin{array}{l}\text { Effectiveness of a self- } \\
\text { guided web-based cannabis } \\
\text { treatment }\end{array}$ & $\begin{array}{l}\text { To test the effectiveness of a self-guided } \\
\text { web-based treatment program for cannabis } \\
\text { use disorder. }\end{array}$ & $\begin{array}{l}\text { The web-based intervention group reported lower frequency } \\
\text { of cannabis use at the 6-week and 3-month follow-ups. At the } \\
\text { 6-week assessment participants reported a lower quantity of } \\
\text { cannabis consumed, but at the 3-month follow-up it no longer } \\
\text { significantly differed between groups. Dependence levels } \\
\text { were only significantly lower in the experimental group at the } \\
\text { 3-month follow-up. Abuse symptoms were significantly less } \\
\text { reported in the experimental group at the 6-week and 3-month } \\
\text { follow-ups. }\end{array}$ \\
\hline
\end{tabular}


2014 Carroll Computer-assisted delivery

et al. of cognitive-behavioral

therapy: Efficacy and

durability of CBT4CBT

among cocaine-dependent

individuals maintained on

methadone
To evaluate the efficacy of the CBT4CBT in helping with the treatment of cocaine users.

The CBT4CBT-assigned group had better results compared to the standard treatment group. Members of the CBT4CBT group were significantly more likely to attain 3 or more consecutive weeks of abstinence. Differences in urinalysis results between groups were not statistically significant. The 6-month follow up revealed continued improvement for those assigned to the CBT4CBT group. 


\section{WEB-BASED INTERVENTIONS FOR ILLICIT DRUG USERS}

\section{Theoretical approach}

We observed different approaches in the interventions proposed by the authors: Motivational Interviewing, Contingency Management, Relapse Prevention and Community Reinforcement Approach. Despite the different approaches, all authors mention that the treatments were based on Cognitive Behavior Therapy (CBT). Two only used CBT in their interventions (Parr, Kavanagh, Young, \& Mitchell, 2011; Carroll, et al., 2014), one only used CRA (Acosta, Marsch, Xie, Guarino, \& Aponte-Melendez, 2012)and the other four combined different approaches. Bickel, Marsch, Buchhalte and Badger (2008) combined CRA and contingency management, Schaub, Sullivan, Haug and Stark (2012) used an intervention that combined CBT, motivational interviewing, relapse prevention and self-control techniques. Rooke, Copeland, Norberg, Hine andMcCambridge (2013) combined CBT and motivational interviewing in their study and Budney et al. (2011) used motivational interviewing, CBT and contingency management.

\section{Drug types}

The studies offered interventions for users of different drugs. Cannabis users participated in the studies of Budney et al. (2011) and Rooke et al. (2013). Benzodiazepine users were treated in the intervention by Parr et al. (2011). Carroll et al. (2014) e Schaub et al.(2012) worked with cocaine users. Opioid users were treated in the interventions by Bickel et al. (2008) and Acosta et al. (2012).

\section{Intervention model}

After investigating the reports from computer-based interventions for illicit psychoactive substance users, it became clear that there were differences as to how the intervention is executed. All studies offered a self-guided treatment, in which the patient uses the computer software without remote mediation by a therapist, such as a chat or videoconference. The differences observed between interventions were that some offered access to the software in conjunction with therapy sessions or with the support of a therapist present. Access to the software was in the treatment clinic(Acosta et al., 2012; Bickel et al., 2008; Budney et al., 2011; Carroll et al. 2014). Other interventions offered self-guided software, but with remote access, instructing the patient to access the intervention software from their own homes, without direct contact with a therapist or researchers (Parr et al., 2011; Rooke et al., 2013;Schaub et al., 2012).

\section{Intervention duration}

Intervention duration varied between studies, as well as the way it was measured, since each intervention had a different format. Some were measured in months, others in weeks, and intervention frequency also varied between studies. Most offered a short termtreatment, except for the studies by Acosta at al. (2012) and Bickel et al. (2008). The study by Acosta at al. (2012) had a length of 12 months and offered a total of 65 sessions per patient. The intervention by Bickel et al. (2008) lasted for 23 weeks with 69 sessions per patient. Users who participated in the study by Budney et al. (2011) had access to 9 intervention sessions that could be completed in up to 12 weeks. The program by Carroll et al. (2014) offered 8 modules to be completed in up to 8 weeks. The study by Parr et al. (2011) sent a total of 13 newsletters (via e-mail) over 3 months. Rooke et al. (2013) proposed a six module intervention in six weeks. The study by Schaub et al. (2012) offered participants a 12 module intervention to be completed in 6 weeks. 


\section{Research design and methodology}

In compliance with the inclusion criteria for this review, only empiric studies were accepted for analysis, with the inclusion of randomized clinical trials and intervention pilot studies. Budney et al. (2011) and Parr et al. (2011) conducted pilot studies. Acosta et al. (2012), Bickel et al. (2008), Carroll et al. (2014), Rooke et al. (2013) and Shaub et al. (2012) conducted randomized clinical trials, and were for that reason considered the ones that provided the best evidence and were considered the studies with the most appropriate methodology, but some information regarding several methodological aspects was still lacking, and will be described below.

\section{Included population}

The criteria for the selection of the population to be included in the studies varied between them. Most studies only offered treatment for those over the age of 18 (Acosta et al., 2012; Bickel et al., 2008; Budney et al., 2011; Carroll et al., 2014; Rooke et al., 2013; Schaub et al., 2012) and the study by Parr et al. (2011) didn't describe age characteristics of their sample. The DSM-IV specific criteria for identifying dependency of each drug were used in four studies (Acosta et al., 2012; Bickel et al., 2008; Budney et al., 2011; Carroll et al., 2014), while the other three used their own inclusion criteria (Parr et al., 2011; Rooke et al., 2013; Schaub et al., 2012). Comparison between studies may be difficult due to the very different inclusion criteria, creating an uneven sample in regards to the severity of the dependency and the chosen population's general characteristics.

In the randomized clinical trial conducted by Acosta et al. (2012), 160 participants, between the ages of 20 and 64, 80 of them in the experimental group and 80 in the control group, were selected in a local methadone maintenance clinic. The study didn't mention any withdrawals or exclusions before the trial started.

The study by Bickel et al. (2008) offered a treatment for opioid-dependent patients in a methadone maintenance clinic. 181 patients were evaluated for participation, but only 135 took part in the study. The program was advertised for two years through radio, television, newspapers and by doctors and other clinics. The pilot study by Budney et al. (2011) recruited participants through newspaper advertisements, posters and through professionals in the field. The sample had 38 participants, but the study didn't mention how many showed interests and/or attempted to be part of the program.

Carroll et al. (2014) recruited 154 cocaine dependent individuals in a methadone clinic, of which 101 were eligible for the trial. 93 patients started treatment and 69 completed the 8-week intervention. The average age of the participants wasn't reported. The pilot study by Parr et al. (2011) had 32 participants start treatment, with 21 taking part in the 3-month follow-up assessment and 14 completing the 14-month follow-up assessment. The program was advertised in mental health and benzodiazepine-related websites. The paper didn't mention how many possible participants attempted to take part in the treatment and the participant inclusion and exclusion criteria wasn't described clearly. A possible interpretation is that participants should have been using benzodiazepine for at least 3 months and express interest in reducing or stopping consumption.

The randomized clinical trial by Rooke et al. (2013) started with 225 participants, of which 149 completed the 6-week follow-up assessment and 122 completed the 3-month assessment. The paper didn't mention whether there was exclusion of participants besides the volunteers that began treatment. The sample was recruited through online marketing and reached participants from other countries besides the study's country. Treatment was offered to adults with knowledge of the 


\section{WEB-BASED INTERVENTIONS FOR ILLICIT DRUG USERS}

English language and computer use and that had consumed cannabis at least once in the previous month and that had interest in reducing or ceasing consumption, without necessarily fulfilling the dependency or abuse of DSM-IV or ICD-10.

Schaub et al. (2012) had 281 volunteers sign up, of which 196 fulfilled the inclusion criteria: at least 18 years old and had used cocaine at least three times in the last 30 days. The intervention was advertised on the Snow Control website, websites of outpatient treatment centers, websites of national organizations for alcohol and drug prevention, social media platforms, internet forums, newspapers and television reports.

There were no studies directed toward teenagers, a population that could benefit from this approach. Studies invested heavily in marketing, due to how fairly unknown this treatment approach is. It's worth mentioning that some studies were conducted in assistance clinics, implementing the computer-assisted intervention within their context.

\section{Follow-up assessment}

In four studies follow-up assessments were proposed after the end of the interventions (Carroll et al., 2014; Parr et al., 2011; Rooke et al., 2013; Schaub et al., 2012). However, the time between the end of the treatment and the assessments varied between studies. Carroll et al. (2014) applied 3 assessments after the end of the intervention: after one, three and six months. Parr et al. (2011) had follow-up assessments after three and six months. Rook et al. (2013) had an evaluation once the treatment was complete and another after three months. Schaub et al. (2012) proposed three followup assessments, four weeks after the treatment was complete, after six weeks and after six months.

The other three studies did not have follow-up assessments (Acosta et al., 2012; Bickel et al., 2008; Budney et al., 2011). Two of those studies proposed studying the efficacy of the intervention, but didn't have any follow-up measures. According to Flay et al. (2005), for a treatment to be considered effective it must be tested in at least two trials that have at least one long term follow-up measure as well as other criteria such as having defined samples of specific populations, having a rigorous statistical analysis of its data and showing consistent positive effects. The lack of followup assessments makes it so the results of the interventions can't be verified in the medium and long term. In future studies, it would be preferable that authors included follow-up assessments in their studies so that those effects can be observed.

\section{Synthesis ofthe results}

The study by Acosta et al. (2012) aimed to characterize the cognitive functioning of patients entering methadone maintenance treatment, to evaluate the impact of cognitive functioning on the primary outcomes of treatment retention and opioid abstinence in those that received the standard treatment or that received standard treatment and the internet-based intervention in the clinic. The results indicate that among the participants with low cognitive scores before the treatment those that had the standard treatment and the internet-based intervention reported more days of abstinence than those that were only receiving the standard treatment.

The authors mention that the results contribute to overall body of literature indicating that lower levels of cognitive functioning negatively impact substance abuse treatment and that computerassisted interventions can be useful for reducing the negative impact of low cognitive functioning in treatment outcome (Acosta et al., 2012).

The randomized clinical trial by Bickel et al. (2008) had the objective of evaluating the efficacy of a computer-based treatment for opioid-dependent patients in methadone maintenance treatment. 
Results demonstrated that the computer-based treatment and therapist-delivered treatment groups produced higher levels of abstinence compared to those of the standard treatment offered by the clinic. The therapeutic alliance scores were high in all groups, including the computer-based treatment group, that spent a significantly lower time with a therapist. Despite the previous consideration regarding the lack of a follow-up assessment, this study shows satisfactory results such as the therapeutic alliance evaluation. Therapeutic alliance has been regarded as an important measure of results in therapist-delivered studies (Leahy, 2008), and especially in interned-based psychotherapy(Hedman, Andersson, Lekander, \& Ljótsson, 2015).

The pilot study by Budney et al. (2011) aimed to describe the development of a computerized treatment for cannabis use disorders and cannabis dependents and to compare it to therapistdelivered treatment. Results indicated a reduction in the time spent with a therapist in the computerized intervention, and no difference between groups was observed in regard to the average continuous weeks of abstinence. Participants evaluated the computerized intervention positively. Most used cannabis almost daily and started consumption at an average age of 14.9 years and started treatment at an average age of 32.9 years.

The clinical trial by Rooke et al. (2013) offered a self-guided internet-based intervention for cannabis users and compared them to a control group that received educational information for six weeks, also through the internet. Results showed that the participants in the internet-based intervention reported a lower frequency of cannabis consumption and less abuse symptoms in the six-week and three-month follow-up assessments. The cannabis unit consumption was lower in the 6-week assessment, but in the 3-month assessment the effect wasn't statistically significant. Cannabis dependency levels were significantly lower in the experimental group in the 3-month assessment.

Carroll et al. (2014) evaluated the Computer-Based Training for Cognitive-Behavioral Therapy (CBT4CBT) software in the treatment of cocaine users. Results showed that the experimental group, which used the CBT4CBT software, attained 3 or more consecutive abstinence weeks than the standard treatment group and the duration of the effect in the experimental group was higher in the 6-month follow-up assessment. And even though there wasn't a significant difference, the experimental group had more urinalysis samples with no drugs and cocaine. The experimental group participants also completed $73 \%$ of the offered CBT4CBT sessions.

The intervention proposed by Schaub et al. (2012) was also directed toward cocaine users. Results indicated that the experimental group completed more modules and stayed for longer in the internet-based intervention than the control group that received psycho-informative modules through the internet. A reduction in the weekly use of cocaine occurred in both groups, as well as low response rates in the follow-up assessment. The only study directed toward benzodiazepine users (Parr et al., 2011) reported significant change in the weekly doses of diazepam and that this change was maintained after three and six months. Participants rated the newsletters they received positively.

Drug consumption, be it abusive or due to a dependency, causes many public health problems and has social costs. Taking the lack of treatment options available for this population already discussed in this paper into consideration, it's necessary to find alternatives that can reach these users. The internet and computer software can be powerful tools in providing effective and efficient treatment. There were few studies that sought evidence to support the use of computer-assisted interventions for illicit drug users that fit the search criteria for this review. Considering that using virtual and automated tools is possible an ever increasingpercentage of the population, investigating the quality and characteristics of interventions through this medium becomes not only relevant but 


\section{WEB-BASED INTERVENTIONS FOR ILLICIT DRUG USERS}

also an ethical duty, since it can offer professionals scientific evidence for an alternative type of intervention. The Brazilian federal council of psychology (Conselho Federal de Psicologia - CFP) regularized psychological services delivered through the internet and other technological means of communication and recognizes those services as long as they are focused in a theme, informative and specific, and limits the number of virtual sessions to 20 or less (asynchronous or concurrent). Psychotherapeutical intervention can only be made experimentally. The CFP considers the existing evidence for web-based psychotherapy not sufficient. The federal council of medicine (Conselho Federal de Medicina) and the council of the state of São Paulo (Conselho Regional de Medicina do Estado de São Paulo) also orient their members in regards to telemedicine and have a manual on ethical principles for medicine-related websites.

Even though the theoretical approach used wasn't clearly described in some papers, all of the computer software used had cognitive behavioral therapy as a base. Five studies proposed brief interventions, with a duration of 12 weeks at most. This result was found in other licit drug studies(Deady, Kay-Lambkin, Teesson, \& Mills, 2014; Donovan, Wood, Frayjo, Black, \& Surette, 2012).

The proposed programs were mainly directed towards cannabis, cocaine and opioid users, an expected result considering those are the most consumed illicit drugs (United Nations Office on Drug and Crime, 2015). It's worth mentioning that the benzodiazepine program can be an important tool for users of a drug that is likely underreported (Duarte, Stempliuk, \& Barroso, 2009). Despite some methodological limitations present in some studies, such as the lack of follow-up assessments, clinical trials seemed to be conducted satisfactorily.

All studies were directed towards adults. No studies worked with a young or teenage population that could benefit even more than adults from a web-based cannabis intervention, as an example. There were also no interventions for specific populations, such as women and the elderly. On the other hand, most studies used diagnostic criteria, focusing their interventions on individuals diagnosed with abuse and/or dependency.

Although there was a categorization of studies, many inconsistencies within the categories were observed. The differences regarding research design, intervention design, selection criteria and theoretical approaches used makes properly comparing studiesa difficult task. This problem may result from the small number of papers analyzed, which could indicate that this is an area of research that needs more studies.

Despite the considerations on methodology, the studies' results were satisfactory, indicating that computer-assisted interventions, with or without a mediator, in a clinical setting or through the internet, seem to be a promising option for helping in the treatment of illicit drug users. Some of the presented studies demonstrated no difference in results between therapist-delivered or computerassisted interventions (Budney et al., 2011; Rooke et al., 2013) and some even presented better results than the standard treatment (Bickel et al., 2008; Carroll et al., 2014). This study only assessed randomized clinical trials, future revisions could include studies with less research design limitations.

\section{ACKNOWLEDGMENT}

We thank the Conselho Nacional de DesenvolvimentoCientífico e Tecnológico (CNPq) that support this study. We thank the Programa de ExtensãoUniversitária for the fellowships, and we thank the Coordenação de Aperfeiçoamento de Pessoal de Nível Superior (CAPES). 


\section{REFERENCES}

Acosta, M. C., Marsch, L. A., Xie, H., Guarino, H., \& Aponte-Melendez, Y. (2012). A webbased behavior therapy program influences the association between cognitive functioning and retention and abstinence in clients receiving methadone maintenance treatment. Journal of Dual Diagnosis, 8(4), 283-293. doi:10.1080/15504263.2012.723317

Balhara, Y. P., \& Verma, R. (2014). A review of web based interventions focusing on alcohol use. Annals of medical and health sciences research, 4(4), 472-480. doi: 10.4103/21419248.139272

Bickel, W. K., Marsch, L. A., Buchhalter, A. R., \& Badger, G. J. (2008). Computerized behavior therapy for opioid-dependent outpatients: A randomized controlled trial. American Psychological Association, 16(2), 132-143. doi: 10.1037/1064-1297.16.2.132

Brown, C. H., Ten Have, T. R., Jo, B., Dagne, G., Wyman, P. A., Muthén, B., \& Gibbons, R. (2009). Adaptative Designs for Randomized Trials in Public Health. Annual Review of Public Health, 30. doi: 10.1146/annurev.publhealth.031308.100223

Budney, A. J., Fearer, S., Walker, D. D., Stanger, C., Thostenson, J., Grabinski, M., \& Bickel, W. K. (2011). An initial trial of a computerized behavioral intervention for cannabis use disorder. Drug and Alcohol Dependence, 115(1), 74-79. doi:10.1016/j.drugalcdep.2010.10.014

Carlini, E. A., Galduróz, J. C., Silva, A. A., Noto, A. R., Fonseca, A. M., Carlini, C. M., et al. (2005). II Levantamento domiciliar sobre o uso de drogas psicotrópicas no Brasil: estudo envolvendo as 108 maiores cidades do país. Páginas \& Letras. doi: CDD-362.2907230981

Carroll, K. M., Kiluk, B. D., Nich, C., Gordon, M. A., Portnoy, G. A., Marino, D. R., \& Ball, S. A. (2014). Computer-assisted delivery of cognitive-behavioral therapy: Efficacy and durability of CBT4CBT among cocaine-dependent individuals maintained on methadone. American Journal of Psychiatry, 171(4), 436-444.doi: 10.1176/appi.ajp.2013.13070987

Copeland, J., \& Martin, G. (2004). Web-based interventions for substance use disorders: A qualitative review. Journal of Substance AbuseTreatment, 26(2), 109-116. doi: 10.1016/S07405472(03)00165-X

Corrigan, P. (2004). How Stigma interferes with mental health care. American Psychologist, 59(7). doi: 10.1037/0003-066X.59.7.614

Deady, M., Kay-Lambkin, F., Teesson, M., \& Mills, K. (2014). Developing an integrated, internet-based self-help programme for young people with depression and alcohol use problems. Internet Interventions, 1(3), 118-131. doi: 10.1016/j.invent.2014.06.004

Dedert, E., Williams Jr, J. W., Stein, R., McNeil, J., McDuffie, J., Ross, I., et al. (2014). Evidence Report: e-Interventions for Alcohol Misuse. Department of Veterans Affairs (US), Washington (DC).

Donovan, E., Wood, M., Frayjo, K., Black, R. A., \& Surette, D. A. (2012). A randomized, controlled trial to test the efficacy of an online, parent-based intervention for reducing the risks associated with college-student alcohol use. Addictive behaviors, 37(1), 25-35. doi: 10.1016/j.addbeh.2011.09.007. Epub 2011 Sep 10

Duarte, P. C., Stempliuk, V. A., \& Barroso, L. P. (2009). Relatório Brasileiro sobre Drogas. Secretaria Nacional de Políticas sobre Drogas, Ministério da Justiça, Brasília.

Flay, B. R., Biglan, A., Boruch, R. F., Castro, F. G., Gottfredson, D., Kellam, S., ... Ji, P. (2005). Standards of evidence: Criteria for efficacy, effectiveness and dissemination. Prevention science, 6(3), 151-175. doi: 10.1007/s11121-005-5553-y 


\section{WEB-BASED INTERVENTIONS FOR ILLICIT DRUG USERS}

Gregório, G. T. (2012). Setting priorities for mental health research in Brazil. Revista Brasileira de Psiquiatria, 34(4), 434-439. doi: 10.1016/j.rbp.2012.05.006

Hedman, E., Andersson, E., Lekander, M., \& Ljótsson, B. (2015). Predictors in Internetdelivered cognitive behavior therapy and behavioral stress management for severe health anxiety. Behaviour research and therapy, 64, 49-55. doi: 10.1016/j.brat.2014.11.009

Leahy, R. L. (2008). The Therapeutic Relationship in Cognitive-Behavioral Therapy. Behavioural and Cognitive Psychotherapy, 36(6), 769-777. doi: 10.1017/S1352465808004852

Olmstead, T. A., Ostrow, C. D., \& Carroll, K. M. (2010). Cost effectiveness of computerassisted training in cognitive-behavioral therapy as an adjunct to standard care for addiction. Drug and Alcohol Dependence, 110(3), 200-207. doi: 10.1016/j.drugalcdep.2010.02.022

Parr, J. M., Kavanagh, D. J., Young, R. M., \& Mitchell, G. (2011). Acceptability of cognitivebehavior therapy via the internet for cessation of benzodiazepine use. Drug and Alcohol Review, 30(3), 306-314. doi:10.1111/j.1465-3362.2010.00183.x

Rooke, S., Copeland, J., Norberg, M., Hine, D., \& McCambridge, J. (2013). Effectiveness of a self-guided web-based cannabis treatment program: Randomized controlled trial. Journal of Medical Internet Research, 15(2), 26.doi: 10.2196/jmir.2256

Schaub, M. P., Haug, S., Wenger, A., Berg, O., Sullivan, R., Beck, T., \& Stark, L. (2013). Can reduce- the effects of chat counseling and web-based self-help, web-based self-help alone and waiting list control program on cannabis use in problematic cannabis users: a randomized controlled trial. BMC Psychiatry, 13(1), 305. doi: 10.1186/1471-244X-13-305

Schaub, M., Sullivan, R., Haug, S., \& Stark, L. (2012). Web-based cognitive behavioral self-help intervention to reduce cocaine consumption in problematic cocaine users: Randomized controlled trial. Journal of Medical Internet Research, 14(6), 166.doi: 10.2196/jmir.2244

Tait, R. J., McKetin, R., Kay-Lambkin, F., Bennett, K., Tam, A., Bennett, A., ... Griffiths. (2012). Breakingtheice: a protocol for a randomised controlled trial of an internet-based intervention addressing amphetamine-type stimulant use. BMC psychiatry, 12(1), 1. doi: 10.1186/1471-244X-12-67

Tait, R. J., McKetin, R., Kay-Lambkin, F., Carron-Arthur, B., Bennett, A., Bennett, K., ... Griffiths, K. M. (2014). A web-based intervention for users of amphetamine-type stimulants: 3month outcomes of a randomized controlled trial. Journal of Medical Internet Research Mental Health, 1 (1). doi: 10.2196/mental.3278

United Nations Office on Drug and Crime. (2015). World Drug Report. United Nations, Office on Drug and Crime. 